\title{
Práticas extensionistas auxiliando no descarte correto de medicamentos
}

\author{
Extension practices assisting in the correct disposal of medicines
}

\author{
Flavia Cristina Ferreira ${ }^{1}$ Ana Carolina Martins Behenck ${ }^{2}$ Danielle Alexandre Costa $^{3}$ Zoe Paulina Feuser $^{4}$ \\ Marília Schutz Borges ${ }^{5}$ \\ 1 Discente. Universidade do Extremo Sul Catarinense (UNESC), Brasil. E-mail: flaviaacristina@unesc.net \\ 2 Discente. Universidade do Extremo Sul Catarinense (UNESC), Brasil. E-mail: anac.behenck@hotmail.com \\ 3 Discente. Universidade do Extremo Sul Catarinense (UNESC), Brasil. E-mail: danielleacosta1@outlook.com \\ 4 Mestre. Professora Universidade do Extremo Sul Catarinense (UNESC), Brasil. E-mail: zoefeuser@hotmail.com \\ 5 Mestre. Professora Universidade do Extremo Sul Catarinense (UNESC), Brasil. E-mail: msb@unesc.net
}

Recebido em: 03/07/2020 | Aprovado em: 01/12/2020

DOI: $10.12957 /$ interag.2020.52361

\section{Resumo}

As sobras de medicamentos domiciliares geram acúmulo de resíduos que permanecem estocados por um longo período, e quando ultrapassam sua validade são descartados na maioria das vezes no lixo doméstico. A prática incorreta de descarte de resíduos de saúde coloca em risco todo o meio ambiente, contaminando o solo, a água, os animais, alimentos, e, por consequência, a saúde humana. A Farmácia Solidária é um projeto de extensão que surgiu em agosto de 2006, com o intuito de propor o descarte correto de medicamentos e o uso racional dos mesmos, promovendo o acesso gratuito aos insumos doados pela comunidade. No período de 2009-2019, o projeto segregou $11.542,18 \mathrm{~kg}$ de medicamentos, gerando o destino correto para os resíduos, podendo perceber que a Farmácia Solidária atinge positivamente a população e obtém números progressivos na conscientização e realização da prática do descarte correto.

Palavras-chave: Farmácia Solidária; Descarte de Medicamentos; Meio Ambiente; Relações Comunidade- Instituição.

\begin{abstract}
The remnants of home medicines generate accumulation of residues that remain stored for a long period, and when they exceed their validity, they are most often discarded in household waste. The incorrect practice of disposing of health residues endangers the entire environment, contaminating the soil, water, animals, food, and, consequently, human health. The Solidarity Pharmacy is an extension project that appeared in August 2006, with the aim of promoting the correct disposal of medicines and the rational use of them, it promotes free access to inputs donated by the community. In the 2009-2019 period, the project segregated $11,542.18 \mathrm{~kg}$ of medicines, promoting the correct destination for waste, and it can be perceived that the Solidarity Pharmacy positively affects the population and obtains progressive numbers in the awareness and carrying out the practice of correct disposal.
\end{abstract}

Área temática: Saúde.

Linha de extensão: Fármacos e Medicamentos. 


\section{Introdução}

Promover educação em saúde é ter a interação entre os profissionais e a comunidade, respeitando os conhecimentos e experiência do próximo e estimulando novos aprendizados. Debater sobre as boas práticas de saúde, bem como esclarecer o porquê das atitudes e como realizar atividades que trarão benefícios para a população e o meio em que vivem é objetivo da educação. Uma destas atitudes, por exemplo, é a conscientização do descarte correto dos medicamentos e o impacto desta ação para a comunidade. ${ }^{1}$

No mundo todo tem sido identificada a presença de fármacos, tanto nas águas, como no solo, devido ao descarte indevido de medicamentos vencidos, parcialmente utilizados ou alterados, e da excreção de metabólitos que não são eliminados no processo de tratamento de esgotos. ${ }^{2}$

Contudo, ainda não existem normas regulatórias para o consumidor final em relação ao descarte de medicamentos e resíduos, fazendo com que muitas vezes a população realize a prática de forma incorreta devido à falta de informação e problemas de logística. ${ }^{3}$

A resolução no 222, de 28 de março de 2018 da ANVISA, regulamenta as boas práticas de gerenciamento dos resíduos de serviços de saúde e dá outras providências. De acordo com o Anexo I, os medicamentos estão enquadrados na categoria B de resíduos, juntamente com outros produtos químicos que representam perigo, como efluentes de processadores de imagens, efluentes de equipamentos automatizados utilizados em análises clínicas, saneantes, entre outros. ${ }^{4}$

No Brasil, o Ministério da Saúde e o Ministério do Meio Ambiente normatizam o descarte correto de resíduos, instruindo as partes envolvidas no manuseio de medicamentos. As autoridades do Ministério da Saúde são responsáveis por inspecionar as empresas ou estabelecimentos que exerçam atividades relacionadas à produção, comércio, manipulação ou uso das substâncias farmacológicas. Por sua vez, o Ministério do Meio Ambiente deve garantir que o descarte dos resíduos gerados por esses 
estabelecimentos esteja dentro dos regulamentos técnicos estabelecidos pela Legislação Ambiental..$^{5}$

Segundo Decreto no 10.388 de 5 de junho de $2020^{6}$, as drogarias e farmácias estabelecidas como pontos fixos de recebimento são obrigadas a adquirir, disponibilizar e manter, em seus estabelecimentos, dispensadores contentores, na proporção de, no mínimo, um ponto fixo de recebimento de medicamentos vencidos ou em desuso, para cada dez mil habitantes, nos Municípios com população superior a cem mil habitantes.

Cabe às instituições de saúde levar as informações para a população quanto aos métodos e condutas adequadas para o descarte, dando ênfase nos impactos de um descarte incorreto e encaminhando para possiveis pontos de coletas de medicamentos, já que as embalagens dos produtos farmacológicos não fornecem instruções de como proceder com os resíduos. ${ }^{5}$

Portanto, o objetivo deste relato de experiência é apresentar e analisar os dados de descarte de medicamentos realizado pela Farmácia Solidária e relatar como esta contribuição interfere na comunidade.

\section{Metodologia}

Para o desenvolvimento do trabalho, foi realizado um estudo exploratório de caráter descritivo e quantitativo. A coleta de dados referentes aos resultados obtidos pelo projeto de extensão Farmácia Solidária (FS) foi realizada por meio de análise do sistema informatizado, Manifesto de Transporte de Resíduos (MTR) e os relatórios anuais do ano de 2009 a 2019. Os dados foram fornecidos pela farmacêutica responsável técnica do local e pela Coordenação do Projeto de Extensão.

Farmácia Solidária se caracteriza por um projeto de extensão que surgiu em agosto de 2006, com o intuito de promover o uso racional, o descarte correto e também auxiliar a população no acesso gratuito aos medicamentos. Além disso, a Farmácia Solidária, com o apoio de bolsistas do projeto de extensão e acadêmicos do curso de farmácia que realizam campanhas de educação em saúde, através de visitas em escolas do município e 
região, clubes de mães, participação em feiras e eventos e, nas comunidades, com intuito de educar as pessoas de todas as faixas etárias, em Criciúma e região.

Em parceria com a Cruz vermelha de Criciúma, a secretaria de saúde de Criciúma e a Universidade do Extremo Sul catarinense (UNESC), a farmácia funciona há quatorze anos com a colaboração de acadêmicos e funcionários da universidade, com estrutura física dentro da mesma. Todos os atendimentos incluindo os presenciais e por telefone são realizados durante o horário de funcionamento (das 08:00 às 11:15 horas e das 13:00 às 15:30 horas). Os pacientes interessados em utilizar os serviços da farmácia comparecem no horário de atendimento, portando prescrição válida atual de profissionais habilitados e documento de identificação com foto. Após a chegada ao local, os mesmos retiram uma senha disponibilizada por ordem de chegada e aguardam atendimento.

O projeto funciona mediante o recebimento de doações de medicamentos advindos da comunidade, consultórios médicos, indústrias farmacêuticas, entre outros estabelecimentos de saúde, com o intuito de devolver à população de forma gratuita medicamentos seguros para consumo. O recolhimento funciona através de postos de coletas espalhados pelo município de Criciúma ou com a entrega na própria farmácia. Existem postos de coletas em Criciúma, sendo eles: ABADEUS; UNESC (Biblioteca, Clínicas Integradas e na própria Farmácia Solidária); Cruz Vermelha Brasileira; Delegacia Regional de Polícia e todas as Unidades Básicas de Saúde, atendendo a população de Criciúma e região.

Todos os medicamentos que chegam até a farmácia através das doações passam por um rigoroso processo de triagem, no qual é avaliada a embalagem, validade e a consistência do medicamento, estando próprio para consumo ou não. Os medicamentos que estão vencidos ou impróprios para uso são separados em caixas de papelão por sólidos e líquidos, que posteriormente são lacradas, pesadas e descartadas. Após esse processo, a farmacêutica responsável técnica emite o Manifesto de Transporte de Resíduos (MTR) de acordo com a legislação, e os medicamentos são recolhidos semanalmente pela empresa de coleta responsável, instituída pela Secretaria Municipal de 
Saúde de Criciúma. Dessa forma, a Farmácia Solidária realiza o descarte dos medicamentos utilizados pela comunidade em geral, contribuindo para a saúde da população e do meio ambiente.

Com o apoio de bolsistas do projeto de extensão e de acadêmicos do curso de farmácia, realizam-se também saídas de campo a fim de promover educação em saúde em diversos ambientes, como escolas, empresas, eventos abertos, entre outros. Abordam-se diversos temas de extrema importância para a sociedade, como o descarte correto de medicamentos, armazenamento correto de medicamentos, uso racional de medicamentos, entre outros.

\section{Resultados e Discussão}

A preocupação em relação a esses compostos está nos possíveis efeitos à saúde humana e ao ambiente, incluindo espécies animais. Entre as substâncias que causam os danos ambientais graves, é possível destacar os hormônios presentes nos anticoncepcionais, sendo capazes de alterar o sistema reprodutivo de animais aquáticos. Além disso, outro exemplo são os antibióticos, responsáveis por gerar resistência bacteriana ao entrar em contato com as bactérias presentes no meio. ${ }^{5}$

De acordo com a Figura 1, é possível observar a variação na quantidade de descartes realizados na Farmácia Solidária. No início do projeto, pouca quantidade era segregada devido à falta de conhecimento da população em relação ao mesmo. No ano de 2014, houve um considerável aumento devido à informação através de educação em saúde e na própria Farmácia Solidária, onde é informado que, além das doações, os pacientes podem trazer os medicamentos vencidos ou de que não fazem mais uso para ser descartado. 


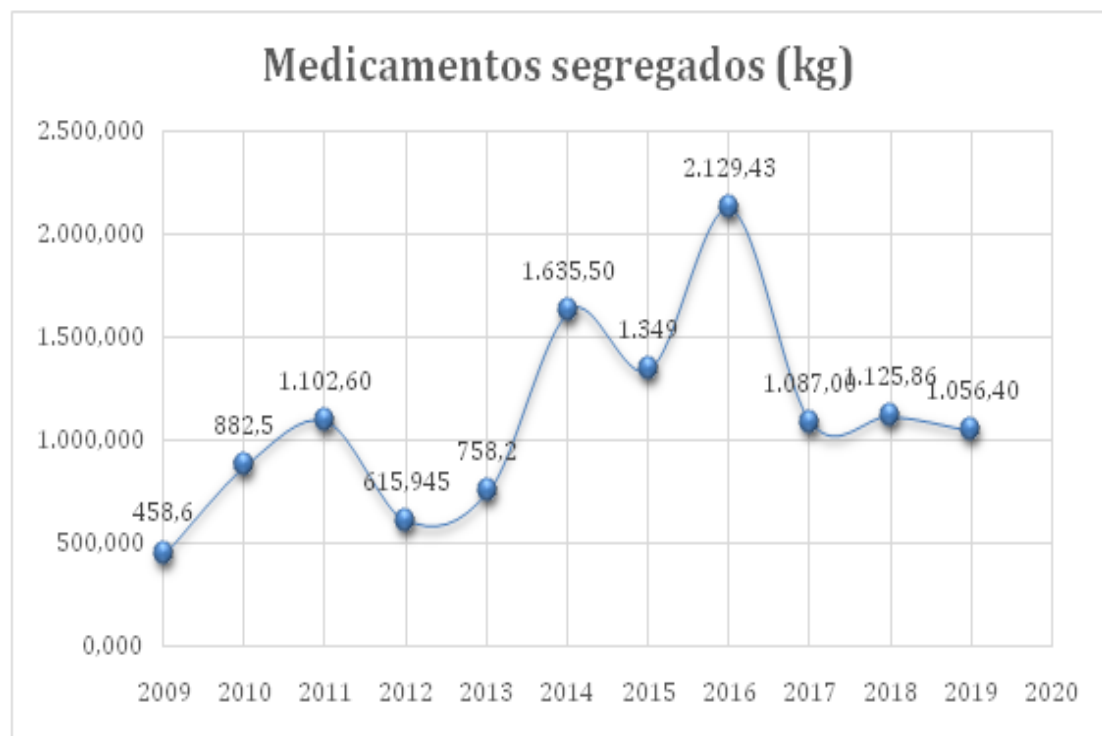

Figura 1 - Medicamentos descartados pelo projeto da FS no período de 2009-2019. Fonte: Próprios autores (2020)

A partir dos resultados representados na Figura 1, pode-se perceber como o papel da educação em saúde é importante para a conscientização da comunidade e o aumento do descarte correto dos medicamentos, já que muitos indivíduos não possuem conhecimentos sobre este assunto devido à falta de informação.

Conforme se passaram os anos e foram sendo realizadas as ações comunitárias, o número de recebimento de medicamentos da comunidade para o descarte correto aumentou, durante o período de 2009-2019, o serviço segregou 11.542,18kg e, ao longo do último ano, em 2019, segregou-se 1.056,40 kg. Ou seja, mesmo que haja variações na quantidade de insumos segregados, o acesso à informação contribuiu para a sociedade de modo positivo, aumentando a conscientização das pessoas permitindo-lhes o acesso para realizar esta prática.

Durante o ano de 2019, o projeto arrecadou medicamentos de diferentes estabelecimentos. São eles: Comunidade em geral (biblioteca, doações diretas na Farmácia Solidária), Cruz Vermelha, Grupo Demolay, Consultórios, Unidades Básicas de Saúde do município de Criciúma, Prefeitura de Maracajá, Centro Espírita Seara de Jesus, Nossa Casa, Almoxarifado da Saúde do município de Criciúma, AFASC, Prefeitura de 
Forquilhinha, Prefeitura de Cocal do Sul, Prefeitura de Passo de Torres, Vigilância Sanitária, Prefeitura Praia Grande, Asilos do município de Criciúma, Amostra grátis de consultórios, Siderópolis, 24h da Próspera, Farmácia do PAM, Vigilância Epidemiológica e Farmácia Judicial, Prefeitura de Jaguaruna, Ações da Farmácia Solidária, Desafio Jovem, CAPS II, GEREC e COMAD, LaModa, CAPS, Gincana SIPAT, Escola Estadual Princesa Isabel (Morro da Fumaça), Hospital da UNIMED, Casa Guido e Prefeitura de Maracajá.

Nas ações em saúde realizadas pelas extensionistas são abordados diversos temas, entre eles sobre a importância do descarte correto e os meios de enviar seus medicamentos impróprios, o que pode ter contribuído para o aumento da quantidade de descarte de medicamentos. O projeto alcançou no ano de 2019 mais de 1.300 pessoas com as ações em saúde, com uma faixa etária entre 6 a 70 anos de idade. No ano de 2019, foram realizadas ações em saúde nos locais segundo a tabela abaixo: 


\begin{tabular}{|c|c|c|c|c|}
\hline Data & Atividade/Local & Público alvo & Resultados alcançados & Número de participantes \\
\hline $\begin{array}{l}19 / 03, \\
23 / 04 \\
28 / 05 \\
29 / 05 \\
04 / 06, \\
05 / 06, \\
13 / 06, \\
22 / 08 \\
23 / 08 \\
11 / 09 \\
12 / 09\end{array}$ & $\begin{array}{l}\text { Educação em } \\
\text { Saúde em escolas } \\
\text { públicas de } \\
\text { criciúma e região }\end{array}$ & $\begin{array}{c}\text { Crianças e } \\
\text { Adolescentes }\end{array}$ & $\begin{array}{l}\text { Conscientização da importância do uso } \\
\text { racional de medicamentos e seus agravos, } \\
\text { como a intoxicação, além de seu descarte } \\
\text { correto e perigos ao meio ambiente. } \\
\text { Divulgação do projeto da farmácia solidária, } \\
\text { dando enfoque na importância das doações. }\end{array}$ & 854 \\
\hline $19 / 03$ & $\begin{array}{l}\text { Evento aos } 70 \\
\text { Anos de } \\
\text { emancipação do } \\
\text { Município de } \\
\text { Turvo/Praça }\end{array}$ & Público em geral & $\begin{array}{l}\text { Ação de Saúde para a população do } \\
\text { Município de Turvo; Tipagem sanguínea; } \\
\text { Divulgação da Farmácia Solidária; } \\
\text { Fitoterapia; Aferição de pressão arterial; Uso } \\
\text { racional de medicamentos. }\end{array}$ & 37 \\
\hline $\begin{array}{l}02 / 04 \\
28 / 03 \\
26 / 04 \\
17 / 06 \\
05 / 07 \\
19 / 10\end{array}$ & $\begin{array}{l}\text { Ação em Saúde } \\
\text { nas Praças do } \\
\text { municípios de } \\
\text { Criciúma e região }\end{array}$ & Público em geral & $\begin{array}{l}\text { Conscientização da importância do uso } \\
\text { racional de medicamentos e seus agravos, } \\
\text { como a intoxicação, além de seu descarte } \\
\text { correto e perigos ao meio ambiente, locais } \\
\text { de armazenamento nos domicílios. } \\
\text { Divulgação do projeto da farmácia solidária, } \\
\text { dando enfoque na importância das doações } \\
\text { e descarte dos medicamentos vencidos }\end{array}$ & 193 \\
\hline $03 / 05$ & $\begin{array}{l}\text { Ação em Saúde } \\
\text { na UNESC em } \\
\text { alusão ao Dia do } \\
\text { Uso Racional de } \\
\text { Medicamentos } \\
\text { (Criciúma - SC) } \\
\text { manhã }\end{array}$ & Público em geral & $\begin{array}{l}\text { Conscientização da importância do uso } \\
\text { racional de medicamentos e seus agravos. } \\
\text { Divulgação do projeto Farmácia Solidária, } \\
\text { dando enfoque na importância das doações } \\
\text { e descarte dos medicamentos vencidos e } \\
\text { disponibilizamos caixas para recolhimento } \\
\text { dos medicamentos doados. }\end{array}$ & 28 \\
\hline $06 / 06$ & $\begin{array}{l}\text { Ação em Saúde } \\
\text { na Metalúrgica } \\
\text { Brametal e Ação \& } \\
\text { Reação (Criciúma) }\end{array}$ & Público em geral & $\begin{array}{l}\text { Conscientização da importância do uso } \\
\text { racional de medicamentos e seus agravos, } \\
\text { como a intoxicação, além de seu descarte } \\
\text { correto e perigos ao meio ambiente. } \\
\text { Divulgação do projeto da farmácia solidária, } \\
\text { dando enfoque na importância das doações. }\end{array}$ & 65 \\
\hline
\end{tabular}




\begin{tabular}{|c|c|c|c|c|}
\hline $24 / 06$ & $\begin{array}{l}\text { Educação em } \\
\text { Saúde no Grupo } \\
\text { de Idosos do } \\
\text { Bairro Nossa } \\
\text { Senhora da Salete } \\
\text { (Criciúma) }\end{array}$ & Idosos & $\begin{array}{l}\text { Durante a tarde do dia } 24 \text { de junho, as } \\
\text { extensionistas do projeto Farmácia Solidária } \\
\text { realizaram uma palestra para o grupo de idosos } \\
\text { do bairro Nossa Senhora da Salete. Em parceria } \\
\text { com as residentes de saúde coletiva do Programa } \\
\text { de Residência Multiprofissional da UNESC, as } \\
\text { extensionistas apresentaram o tema uso racional } \\
\text { de medicamentos, com enfoque nos perigos da } \\
\text { automedicação, armazenamento e descarte de } \\
\text { medicamentos, assim esclareceram dúvidas sobre } \\
\text { fracionamento e vencimento dos mesmos. } \\
\text { Sempre divulgando e destacando a importância } \\
\text { da doação de medicamentos que não tem mais } \\
\text { utilidades, a extensionistas tiram dúvidas e } \\
\text { apresentam como funciona o projeto }\end{array}$ & 12 \\
\hline 05/09 & $\begin{array}{c}\text { Roda de conversa } \\
\text { CAPS II } \\
\text { (Criciúma) }\end{array}$ & Público em geral & $\begin{array}{l}\text { Conscientizar os usuários do CAPS II por } \\
\text { meio de dinâmicas e conversas sobre o uso } \\
\text { racional de medicamentos, o uso de plantas } \\
\text { medicinais, o descarte adequado, o } \\
\text { armazenamento correto e os riscos } \\
\text { envolvidos, a fim de informatizar, corrigir e } \\
\text { auxiliar em alguns hábitos relacionados a } \\
\text { medicamentos. }\end{array}$ & 2 \\
\hline $07 / 09$ & $\begin{array}{l}\text { Desfile } 7 \text { de } \\
\text { Setembro } \\
\text { (Criciúma) }\end{array}$ & Público em geral & $\begin{array}{l}\text { Divulgar o projeto da Farmácia Solidária que } \\
\text { tem como intuito receber os medicamentos } \\
\text { vencidos ou não da comunidade, de } \\
\text { consultórios, de ações, assim realizando o } \\
\text { descarte correto dos mesmos ou o } \\
\text { fornecimento racional aos seus pacientes. }\end{array}$ & 60 \\
\hline $\begin{array}{l}01 / 10 \\
03 / 10 \\
07 / 10\end{array}$ & $\begin{array}{l}\text { Tarde de extensão } \\
\text { no CRAS de } \\
\text { diferentes bairros } \\
\text { de Criciúma }\end{array}$ & Público em geral & $\begin{array}{l}\text { Conscientizar a comunidade, adolescentes e } \\
\text { crianças do bairro Santa Luzia, usuários do } \\
\text { CRAS, sobre o uso racional de } \\
\text { medicamentos, o descarte correto dos } \\
\text { mesmos e esclarecimento de dúvidas. }\end{array}$ & 60 \\
\hline $\begin{array}{l}03 / 10 \\
10 / 10 \text { e } \\
21 / 10\end{array}$ & $\begin{array}{l}\text { Visitas aos } \\
\text { consultórios } \\
\text { médicos }\end{array}$ & $\begin{array}{l}\text { Consultórios } \\
\text { médicos }\end{array}$ & $\begin{array}{l}\text { Diminuir as sobras de medicamentos nos } \\
\text { consultórios médicos, conscientizando a } \\
\text { estes profissionais da importância que tais } \\
\text { medicamentos têm para a população que } \\
\text { utiliza a farmácia solidária. }\end{array}$ & 34 \\
\hline
\end{tabular}

Tabela 1 - Ações extensionistas em saúde realizadas no ano de 2019.

Fonte: Próprios autores (2020)

O descarte correto de medicamentos é uma atividade realizada dentro do projeto.

Entretanto, ainda se faz necessária a execução de trabalhos de conscientização da população, através do projeto de educação em saúde, para ressaltar os riscos e malefícios 
causados ao meio ambiente e aos seres humanos, quando o descarte é realizado sem as devidas precauções necessárias.

A destinação correta dos medicamentos vencidos ou sem utilização no Brasil ainda é um desafio. Embora a Política Nacional de Resíduos Sólidos, publicada em 2010, tenha previsto que os produtos inservíveis sejam devolvidos aos seus produtores originais, isso não acontece da forma devida na realidade, seja por falta de informação das pessoas ou pela ausência de um sistema definido de logística reversa no país. ${ }^{7}$

Com relação às consequências do descarte inadequado de medicamentos, um estudo realizado por Freitas $(2018)^{8}$ teve o objetivo de identificar quais medicamentos estão presentes nas águas residuais que chegam à Estação de Tratamento de Águas Residuais (ETAR) de Criciúma - SC e nas águas superficiais do rio Sangão. Foram encontrados resíduos pertencentes às classes dos anti-hipertensivos, estimulantes, anti-inflamatórios não esteroides, antimicrobiano, anestésicos e antiarrítmico, sendo que a detecção foi maior nas amostras de águas residuais do que nas superficiais ${ }^{8}$.

\section{Considerações Finais}

Os resultados demonstram que a falta de informação para a comunidade pode interferir diretamente no descarte consciente dos medicamentos, ficando clara a necessidade de uma maior sensibilização relacionada a este assunto.

Faz-se necessário, por parte do poder público, estabelecer leis para o gerenciamento de resíduos de saúde no âmbito domiciliar e esclarecer por meio de campanhas educativas a importância do descarte correto e como realizar esta prática, já que a maior parte da comunidade desconhece locais de arrecadação e dos impactos ambientais.

Outra forma de diminuir o descarte incorreto é promover o uso racional de medicamentos, como a extensão de vendas fracionadas e fornecimento de orientações, pois assim o paciente compraria apenas o necessário para seu tratamento, evitando sobras 
e possíveis automedicações. A inserção e a prática destas ações proporcionarão um grande aumento de conscientização da comunidade e um resultado positivo para o meio ambiente.

Os resultados obtidos também permitem evidenciar a importância que o projeto tem para a sociedade, contribuindo para o autocuidado e bem-estar da população, através da oferta gratuita de medicamentos e da disponibilização da educação em saúde para a comunidade em geral.

\section{Referências}

1. GAZZINELli, M. F.; GAZZINELli, A.; REIS, D.C.; PENNA, C. M. M. Educação em saúde: conhecimentos, representações sociais e experiência da doença. Cadernos de Saúde Pública, v. 21 n.1, p. 200-206, 2005.

2. ALENCAR, Tatiane de Oliveira Silva; MACHADO, Carla Silva Rocha, COSTA, Sônia Carine Cova; ALENCAR, Bruno Rodrigues. Descarte de medicamentos: uma análise da prática no Programa Saúde da Família. Ciência \& Saúde Coletiva, Novo Horizonte, v. 19, n. 7, jul. 2014

3. HOPPE, T. R. G.; ARAÚJO, L. E. B. Contaminação do meio ambiente pelo descarte inadequado de medicamentos vencidos ou não utilizados. Revista Monografias Ambientais, v. 6, n. 6, p.1248-1262, mar/2012.

4. BRASIL, Resolução Da Diretoria Colegiada No 222 de 28 de março de 2018. Dispõe sobre os requisitos de Boas Práticas de Gerenciamento dos Resíduos de Serviços de Saúde. Diário Oficial da União 2018; 28 mar.

5. UEDA, J, TAVERNARO, R, MAROSTEGA, V, PAVAN, W. Impacto ambiental do descarte de fármacos e estudo da conscientização da população a respeito do problema. Revista Ciências do Ambiente On-Line, Campinas, v. 5, n. 1, p. 1-6, jul./ 2009.

6. BRASIL, Decreto $\mathrm{n}^{\circ} 10.388$ de 5 de junho de 2020, Regulamenta o $\S 1^{\circ}$ do caput do art. 33 da Lei no 12.305 , de 2 de agosto de 2010, e institui o sistema de logística reversa de medicamentos domiciliares vencidos ou em desuso, de uso humano, industrializados e manipulados, e de suas embalagens após o descarte pelos consumidores. Diário Oficial da União 2020; 05 jun.

7. JUNIOR, J. G. Falta de política sobre de descarte de medicamentos preocupa. Conselho Federal de Farmácia 2018. Disponível em: 〈http://www.cff.org.br/noticia.php?id=4949>. Acesso em: 29 abr. 2020. 
8. FREITAS, M. D. Análise de contaminantes emergentes no município de Criciúma, SC. Dissertação (Mestrado) - Universidade do Extremo Sul Catarinense, Programa de PósGraduação em Ciências Ambientais, 2018. 